to problems in modern chemical industry. This finds expression in the team-work in which mathematicians, physicists, chemists, biologists, geologists and metallurgists may all participate, and Mr. Cremer thought that, in thus furthering the idea of the unity of science, that co-operation and interchange between universities and industry which is so essential and fruitful may also be stimulated.

Other factors changing the face of chemical industry to which $\mathrm{Mr}$. Cremer referred were the introduction of new constructional materials, with all their implications for the design of plant to operate under more and more exacting conditions of pressure or temperature, the remarkable developments in scientific instruments which are not only increasing the accuracy of control but also making it possible for such control to be automatic or remote, and the contribution of the chemical engineer in the study of selected categories of process operations, based on the same physical principles although their method of application may differ with the properties of the individual product to be manufactured. Besides this, the attention now being given to the safety and welfare of the workers in chemical industry is also affecting its character as well as the design of its plant. The study of occupational diseases has sometimes stimulated research on disease in wider fields, and the industry in its work on toxicology and like matters is concerned with the health and safety of users of its products as well as of those making them. Mr. Cremer believed that the industry is now fully conscious of all its direct and indirect obligations to the public, and that there is now much better prospect of science being properly wedded to industry and, in turn, of industry to civilization.

But it seems equally clear from this symposium that the future of chemical industry will not depend solely on internal factors, but also on whether Government policy and the general social or political climate are favourable. There was implicit concern that fiscal policy may place fresh difficulties in the way of development when obsolescence is so large a consideration and research and development so costly, and whether there will continue to be forthcoming the initiative and individuality, the enterprise and imagination which are required to create and to seize these opportunities.

\section{STUDENT HEALTH IN GREAT BRITAIN}

$I^{\mathrm{N}}$

TRODUCING a symposium on student health before a crowded session at Edinburgh of Section I (Physiology) of the British Association, Sir Andrew Davidson, chief medical officer, Department of Health for Scotland, claimed that no better nor more appropriate recognition of the importance of student health has been recorded than its inclusion in the discussions this year of the British Association. We have been guilty hitherto of neglecting an important group of the community from which not only our men of science but also other leaders of the nation are most likely to come.

Eighty-five thousand full-time students attend universities and colleges under the ægis of the University Grants Committee, and probably as many more attend other central institutions for higher education. In Scotland there are about thirty-one thousand students in all. This very substantial occupational group is subjected to stresses and strains - both physical and mental-which demand special understanding.

The promotion of full health and the prevention of ill-health, with measures for the early diagnosis and treatment of disease, should be the aim of all student health services. Curative medicine must have its place but should, wherever possible, be arranged within the National Health Service. The best features of our school health services and our indus. trial health service should be incorporated-the personal health programme and the health education work of the former, and the environmental effort of the latter. The approach to student health work should be through physiology rather than pathology.

Stressing the importance of health education, Sir Andrew quoted the Goodenough Committee Report. "A student health service would be one of the means of inspiring the community to a sensible interest in the promotion of health. . . . the service would be a special education for them [students] as providing a practical demonstration of medical practitioners in the role of health officers. Such a demonstration related to a student's own health and problems is likely to make a much more lasting impression than much exhortation."

Of particular interest were Sir Andrew's remarks on research in student health services. In no other section of the community do such excellent opportunities exist for research in health. The combination of an intelligent, young, apparently healthy person and a doctor with reasonably adequate time is unique. There is, too, an almost unexplored field of investigation of a group living through one of life's most critical stages. Inquiries into environmental, social and personal factors, physical exercise, nutrition and so forth can provide invaluable information, which may perhaps indicate routes of development in our health services. There is the added advantage that the student can be closely observed for three to five years, while his later history may even be followed up for a longer period. Where can intelligent co-operation be more readily forthcoming, asked Sir Andrew ?

During the limited time available for eye testing in the medical examination of large numbers of students, anything more elaborate than the monocular Snellen test is usually considered to be impossible. This test, however, fails to reveal many instances of binocular defects, anisometropia suppression, and so on. Dr. R. H. Bolton, of the University of Birmingham, described in an impressively lucid paper how he has adapted the Turville infinity balance to provide a 'screening' test, which, though not yet completely infallible, nevertheless provides a simple test markedly superior to any other screening test in his experience. The Turville infinity balance is essentially an extension of the well-known binocular reading test in which a pencil or narrow strip of paper is held between the eyes and the test type. The pencil is replaced by a sand-blasted septum in the centre of a mirror in which back-to-front letters are reflected and read, different letters being read by each eye. This "'gives a satisfactory indication of how the student is using his eyes as a pair and saves a lot of time". By applying a surface-silvered mirror immediately behind a clear-glass septum, but slightly out of alignment, a virtual image of the test letters is seen binocularly immediately above the separated or monocularly seen types, providing a standard for detecting even minor degrees of 'phoria' or faulty 
alignment. At a second testing 'station' each student undergoes a colour vision test, a binocular reading test, and near-point phoria test using a Maddox convergeometer. From the subsequent histories of those examined by him, Dr. Bolton confirms the usual view that 'esophores' are more likely to have eye troubles than 'exophores' or 'orthophores'.

As part of a wider study of the socio-medical and environmental background of 2,539 students of all faculties at the University of Edinburgh, Dr. J. G. Thomson has considered the association of these factors with the academic results achieved by 592 medical students from all years except the first, and by a seccnd group of 137 first-year medical students.

Three-quarters of all students and 83 per cent of medicals were from social classes I and II (the upper social classes). Family size does not show the normal variation between the social classes, and students from lower classes obtain academic results as good as those from other classes.

Students entering the medical faculty at ages between twenty-six and thirty showed the best academic results, followed by those who started at less than eighteen years of age. Of the year-group 18-25, those entering between the ages of twenty and twenty-two gave the poorest results of all. There was no evidence in this group that national servicemen did better or worse than non-servicemen, and, of the physical and environmental factors considered, only myopia showed a slight suggestive association with superior academic performance.

In the first-year group, students living at home did less well than those in lodgings approved by the university welfare superintendent. Room-sharing, longer hours of daily travel-time, and differences in recreational habits did not account for this, and the solution was found in a group of twenty-three students from English secondary schools who were very much more successful than any other group. What appeared to be an interesting environmental difference was, therefore, probably the result of pre-university educational factors, or of varying selection criteria.

Presenting a provocative and enjoyable paper on the relationship between physique and physical attainments, habits and behaviour, including delinquency, Dr. R. Parnell, of the University of Oxford, created a stir with a formula based on physical measurements and radiographic heart-size, which not only differentiated sprinters from long-distance runners, but also graded them according to potential performance. $\mathrm{He}$ confidently predicted that a particular athlete at the top of his table would win the $1,500-\mathrm{m}$. race at the Olympic Games at Helsinki next year.

A comparison of heights and weights in the University of Oxford revealed once again that students from the lower social classes are smaller than those from the other social classes. Since, however, students from government grant-aided schools are "taller and heavier than the highest level reached in the general population", Dr. Parnell argues "that the great difference between undergraduates and the general population is probably due to selection" and not to nutritional advantages. Is it not more probable that working-class parents who are ambitious for their children do, as demonstrated in Dr. Thomson's paper, limit the size of their families in order to give them both educational and nutritional advantages?

The classification of physique by methods of standard photography based on the Sheldon technique, and standardized by the work of Tanner in
Great Britain and Dupertuis in the United States, has produced evidence in support of those who propound a relationship between physique and behaviour. Dr. Parnell demonstrated the use of the 'fat clock', a graphic method of recording physical measurements and the thickness of the subcutaneous fat, which will be a useful technique for all those who are interested in this work.

In a powerful plea for a deeper appreciation of the problems of the tuberculous student, Sir Alan Rook, of the University of Cambridge, estimated that there are probably close on five hundred undergraduates in sanatoria in Great Britain and more than two thousand in need of medical care or observation for pulmonary tuberculosis. After discussing the problems of adjustment and career selection which face those students who are able to continue their studies while under observation, Sir Alan went on to paint a graphic picture of the frustration, the loss of initiative and desire to work, or the fretfulness and restless anxiety of these young people, progressing all too often to a profound psychological maladjustment, which not only retards recovery but also impedes resettlement after cure.

After referring to the success of Continental students' sanatoria, which he reluctantly classed as impracticable in Great Britain at present, Sir Alan asked that, at least, we should establish something corresponding to the Continental post-cure hostels for tuberculous students.

This must not be thought of as preferential treatment any more than rehabilitation units for industrial workers and 'Remploy' factories can be considered 'preferential'. The correct treatment should be available to all, and Continental experience has shown that the correct treatment for university students includes the mental stimulus of continued teaching and study under medical supervision. It is scarcely creditable to British universities to have lagged so far behind Continental practice in this matter. Now, however, the students of Great Britain are pressing strongly for action, and have collected a large sum of money towards this project. It is to be hoped that Sir Alan's plea will bring them the influential support for which they look so hopefully.

As the speakers freely admitted, much of their work is exploratory and open to criticism or even correction. The important thing is that a start has been made. A regular stocktaking of the health, well-being and occupational efficiency of those on whom the advancement of science will depend in the future will be of great interest to members of the British Association, especially if the approach continues to be "through physiology rather than pathology".

\section{ARMAGH OBSERVATORY REPORT FOR 1950}

$T$ HE March issue of the Iresn Astronomical Journal (1, No. 5 ; 1951) contains the report on Armagh Observatory for the year 1950, in which Dr. E. M. Lindsay, the director, gives the main items of interest and development for the year. The ArmaghDunsink-Harvard telescope is now in operation at the Boyden Station of the Harvard Observatory at Mazelspoort, Bloemfontein, where it arrived on October 26, 1950, and was erected under the supervision of Dr. J. S. Paraskevopoulos and Dr. Bok 